\title{
Book Reviews Section
}

In this issue we have included four book reviews. The first review is for a recently published Australian book that documents the experiences of people who have survived a suicide attempt. The second review is for a new Australian textbook of educational psychology. Our next review examines the practical application of Howard Gardner's work on multiple intelligences in UK and US educational settings. The final review is for a new book that is written for parents and caregivers. The focus is on the importance of caregivers understanding children's neural development.

The journal is currently seeking reviewers for the following texts:

1. Teaching in Inclusive School Communities, edited by Suzanne Carrington and Jude MacArthur. Published by Wiley

2. Lifespan Development: A Topical Approach by Michele Hoffnung et al. Published by Wiley

If you are interested in reviewing one of these texts or providing a review of a relevant, new publication please contact me by email.

Gerald Wurf

Book Reviews Editor

Charles Sturt University, Australia

Email: gwurf@csu.edu.au

\section{Turning Points: An Extraordinary Journey Into the Suicidal Mind}

Edited by Diego De Leo

Australian Academic Press, 2010, 204 pp., \$29.95 (AU paperback), ISBN 9781921513374

doi: 10.1017/edp.2012.19

Turning Points is short, only 190 pages, and very easy reading. The book begins and ends with a chapter by the author, Professor Diego De Leo. Diego is a psychiatrist who has spent the last 20 years of his career studying and working in the area of suicide prevention and aftermath, primarily in Italy and Australia. Although Diego says that in this book, 'I wanted to be strong and avoid the temptation of a short course in suicidology', he provides us with some samples of his extensive knowledge of how much we do (and don't) know about suicide.

However, the heart of the book comprises 10 personal accounts from people who survived a suicide attempt, and two accounts from those bereaved by suicide. In each account, the teller describes in raw detail the painful experiences that led to the attempt, and the aftermath and recovery period. 
The thing that struck me the most about these accounts is the unexpectedness of the attempts, even to the survivor, as if a switch were suddenly flicked. In 'Lucia's story', she describes her walk to the balcony she jumped from moments later: 'It was not clear what brought me up there. I needed more air.' She says: 'I had never seriously thought to commit suicide before. I could say that even that day I didn't previously think to kill myself ... It was a kind of sudden decision, something that became clear to me at the very last moment.' This is extremely unsettling for those of us who are trying to predict risk on a daily basis. However, it was also clear that the survivors were in terrible psychological pain for some time before the attempt, and were receiving little or no professional help.

The other surprising thing was the extraordinary epiphany that occurred in some stories at the critical moment of the attempt. Something happened at the point of no return that seemed to trigger a change of perspective. For example, in 'Trevor's Story', he describes trying to move his head out of the way after pulling the trigger, and later saying to himself: 'Fuck this, I don't want to die.' Like Trevor, many of the survivors maintained their determination to live, even throughout recovery from horrendous injuries.

Through this book, Diego encourages us to reflect on the 'turning points' that are in us all, even at our darkest moments, and that 'a Phoenix is actually there, ready to fly again for us'. He emphasises the importance of listening, and finding ways to help people feel more connected, not just with health services, but with each other. He also reminds us that in many cases not recounted in this book, people will try and try again, if their first attempt does not result in death.

However, Turning Points is not a treatment manual, and does not try to provide advice on the 'how to' of suicide prevention. Diego has left this for other publications, and it makes Turning Points refreshingly different. Instead, the authors remind us of the human impact of suicide, and also of our remarkable capacity for recovery, if only we can harness it in time.

Kelly Parkyn

Kingston Psychology Tasmania, Australia

\section{Educational Psychology: First Australian Edition}

Edited by Angela M. O'Donnell, Eva Dobozy, Brendan Bartlett, Fiona Bryer, Johnmarshall Reeve, and Jeffrey K. Smith Wiley, 2012, 676 pp., \$132.95 (AU paperback), ISBN: 978-0-7303-0322-0 doi: 10.1017/edp.2012.20

Teacher quality is the most important school-related factor influencing student achievement. Pre-service teacher training and education must be improved to enhance the quality of teaching in Australian schools and lift student attainment (Council of Australian Governments, 2008; Ministerial Council for Education, Employment, 